\title{
AKTIVITAS ANTIOKSIDAN EKSTRAK DAN FRAKSI KULIT BATANG PILA- PILA (Mallotus paniculatus) TERHADAP 1,1-DIPHENYL-2 PICRYLHIDRAZYL (DPPH)
}

\author{
Riska Harfiani Junaid*, Mirhansyah Ardana, Laode Rijai \\ Laboratorium Penelitian dan Pengembangan FARMAKA TROPIS \\ Fakultas Farmasi Universitas Mulawarman, Samarinda, Kalimantan Timur \\ *email: riskaharfiany@gmail.com
}

\begin{abstract}
ABSTRAK
Pila-pila merupakan tumbuhan yang dapat digunakan untuk pengobatan berdasarkan pengalaman empiris di Melak, Kutai Barat, yang kemudian diduga juga memiliki aktivitas antioksidan. Telah dilakukan penelitian mengenai aktivitas antioksidan dengan berbagai konsentrasi ekstrak metanol, fraksi etil asetat dan fraksi n-heksan kulit batang Pila-pila (Mallotus paniculatus). Ekstrak dan fraksi kulit batang Pila-pila diuji terhadap senyawa DPPH (1,1-difenil-2-pikril-hidrazil) dengan mengukur absorbansi menggunakan spektrofotometer sinar tampak pada panjang gelombang $516 \mathrm{~nm}$. Variasi konsentrasi sampel uji yang digunakan pada pengujian ini adalah 20, 40, 60, 80, dan 100 ppm untuk ekstrak metanol dan fraksi n-heksan serta 10, 20, 30, 40, 50 ppm untuk fraksi etil asetat. Hasil penelitian menunjukkan bahwa ekstrak kulit batang pila-pila merupakan antioksidan kuat dengan nilai IC50 71.94 ppm, begitu pula fraksi n-heksan dengan IC50 59.92 ppm. Untuk fraksi etil asetat memiliki aktivitas antioksidan sangat kuat yaitu dengan nilai IC50 49.92 ppm.

(IC50 ekstrak metanol $=71.94$ ppm, IC50 fraksi n-heksan $=59.92 \mathrm{ppm}$, IC50 fraksi etil asetat $=49.92 \mathrm{ppm})$.
\end{abstract}

Kata kunci : Antioksidan, Mallotus paniculatus, DPPH.

\section{ABSTRACT}

Pila-pila is a plant which is used as medicine based on empirical evidence in Melak, West Kutai, so this plant predicted has an antioxidant activity. An investigation about antioxidant activity of methanolic extract, fraction ethylacetate and fraction n-hexane from Pila-pila cortex (Mallotus paniculatus). Extract and fractions from Pila-pila cortex was tested using DPPH (2,2-diphenyl-1-picrylhydrazyl) by measuring absorbance with visible light spectrophotometer at a wavelength of $516 \mathrm{~nm}$., determination of the extract and fractions from Pila-pila cortex concentrations required for $50 \%$ inhibition of DPPH radical scavenging effect (IC50). The variation concentration of methanolic extract and fraction $n$ hexane are 20,40,60,80, $100 \mathrm{ppm}$ and 10,20,30,40,50 ppm for fraction ethylacetate. The results showed that methanolic extract Pila-pila cortex have strong antioxidant activity with IC50 value of 71,94 ppm, likewise fraction n-hexane with IC50 value of $59.92 \mathrm{ppm}$ and then fraction ethylacetate showed have very strong antioxidant activity with IC50 value of ppm $49.92 \mathrm{ppm}$. (IC50 of ascorbic acid $=3.35 \mathrm{ppm}$, IC50 of essential oil $=16.29 \mathrm{ppm}$, IC50 of ethanolic extract $=38.89 \mathrm{ppm}) .($ IC50 of methanolic extract $=71.94 \mathrm{ppm}$, IC50 of fraction $n$-hexane $=59.92 \mathrm{ppm}$, fraction ethylacetate $=49.92 \mathrm{ppm})$.

Keywords : Antioxidant, Mallotus paniculatus, DPPH. 


\section{PENDAHULUAN}

Salah satu tanaman yang dipercaya oleh masyarakat Melak, Kutai Barat yang mempunyai banyak khasiat ialah Pila-pila (Mallotus paniculatus (Lam.) Mull.Arg.,). Tumbuhan Pila-pila merupakan salah satu tumbuhan obat Indonesia yang dipercaya oleh masyrakat memiliki khasiat penyembuhan.

Tumbuhan Pila-pila umumnya digunakan sebagai obat keracunan, gatal-gatal dan diare. Tumbuhan Pila-pila merupakan semak dengan tinggi 10 hingga $15 \mathrm{~m}$ yang terdiri dari batang, daun, bunga, buah dan biji. Tumbuhan ini dapat ditemukan Cina Selatan, Taiwan, dan India. Selain itu, terdapat juga di Indonesia, terutama di daerah Kalimantan, Sulewesi, dan Sumatera (JFW, 2009).

Antioksidan merupakan senyawa pemberi elektron (electron donor) atau reduktan. Senyawa ini memiliki berat molekul kecil, tetapi mampu menginaktivasi berkembangnya reaksi oksidasi, dengan cara mencegah terbentuknya radikal. Antioksidan juga merupakan senyawa yang dapat menghambat reaksi oksidasi, dengan mengikat radikal bebas dan molekul yang sangat reaktif (Winarsi, 2007).

Salah satu uji untuk menentukan aktivitas antioksidan penangkap radikal adalah metode DPPH (1,1-Diphenyl-2-Picrylhydrazyl). DPPH secara luas digunakan untuk Mengukur dan membandingkan aktifitas antioksidan senyawa-senyawa fenolik, dan evaluasi aktivitas antioksidan melalui perubahan warna DPPH dari ungu menjadi kuning (Molyneux, 2004).

Kulit batang Pila-pila merupakan bagian berkulit yang mempunyai bau manis, berwarna cokelat dibagian luar dan dapat dengan mudah dilepaskan dari batang. Bagian dalam kulit batang berwarna hijau dan mempunyai kadar air yang tinggi.

Dari penelusuran literatur, sedikit sekali diperoleh informasi ilmiah tentang kandungan metabolit sekunder tumbuhan Pila-pila, walaupun secara tradisional tumbuhan Pila-pila telah dimanfaatkan sebagai bahan obat oleh masyarakat. Berdasarkan uraian diatas diduga kulit batang Pila-pila mempunyai potensi sebagai antioksidan sehingga perlu dilakukan identifikasi kandungan golongan metabolit sekunder dan uji aktivitas antioksidan dari kulit batang Pila-pila.

\section{METODE PENELITIAN}

\section{Bahan}

Bahan yang diteliti adalah tumbuhan Pila-pila (Mallotus paniculatus.), bagian yang diteliti adalah kulit batang. Bahan penelitian: air suling, metanol, n-heksanaa, etil asetat, Logam Magnesium Pereaksi Dragendroff dan Pereaksi Mayer asam klorida pekat, serbuk magnesium, besi (III) klorida, asam asetat glasial, asam sulfat pekat. dan pereaksi DPPH (1,1-diphenyl-2-picrylhydrazyl).

\section{Peralatan}

Peralatan yang digunakan dalam penelitian ini antara lain seperangkat alat maserasi, Seperangkat alat gelas yang biasa digunakan di laboratorium, timbangan analitik (Precisa XB 220A), vortex, rotary evaporator (büchi rotavapor R-200), dan tabung reaksi bertutup, mikro pipet, vortex, kuvet, spektrofotometer UVVis (Genesys I0S UV-Vis Spectrophotometer).

\section{Prosedur pengambilan dan pengolahan sampel}

Dipilih kulit batang Pila-pila yang segar. Bagian yang diteliti adalah bagian kulitnya, kemudian dicuci, dipotong kecil-kecil dan dikeringkan dengan diangin-anginkan pada udara terbuka didalam ruangan. Setelah sampel kering dilanjutkan dengan pemotongan 
(perajangan) dan ditimbang simplisia kulit kulit batang Pila-pila. Selanjutnya sampel yang telah dimaserasi dengan metanol, dipekatkan dengan rotary evaporator dan dianginanginkan hingga kering. Ekstrak metanol tersebut kemudian difraksinasi menggunakan pelarut n-heksan dan etil asetat.

\section{Uji Metabolit Sekunder}

\section{a. Uji Alkaloid}

Sebanyak $2 \mathrm{~mL}$ ekstrak diuapkan di atas cawan porselin. Residu yang dihasilkan kemudian dilarutkan dengan $5 \mathrm{~mL} \mathrm{HCl} 2 \mathrm{M}$. Larutan yang diperoleh dibagi ke dalam 3 tabung reaksi. Tabung pertama berfungsi sebagai blanko, ditambahkan dengan 3 tetes $\mathrm{HCl}$ 2 M. Tabung kedua ditambahkan 3 tetes pereaksi Dragendorff dan tabung ketiga ditambahkan 3 tetes pereaksi Mayer. Pada pereaksi Dragendorff akan terbentuk endapan berwarna jinggasedangkan pereaksi Mayer akan terbentuk endapan kuning yang menandakan positif adanya alkaloid [2].

\section{b. Uji Fenol}

Ekstrak sampel sebanyak $1 \mathrm{ml}$ dimasukkan ke dalam tabung reaksi untuk dilakukan pengujian fenolik dengan cara ekstrak ditambahkan pereaksi $\mathrm{FeCl} 31 \%$, jika terjadi warna hitam menunjukkan adanya senyawa Fenolik.

\section{c. Uji Flavonoid}

Sebanyak $2 \mathrm{~mL}$ ekstrak ditambahkan dengan air panas secukupnya, kemudian dididihkan selama 5 menit lalu disaring. Filtrat sebanyak $5 \mathrm{~mL}$ ditambahkan 0,05 mg serbuk $\mathrm{Mg}$ dan $1 \mathrm{~mL} \mathrm{HCl}$ pekat, kemudian dikocok kuat-kuat. Uji positif ditunjukkan dengan terbentuknya warna merah, kuning atau jingga [3].

\section{d. Uji Tanin}

Sebanyak $1 \mathrm{~mL}$ ekstrak ditambahkan dengan beberapa tetes larutan besi(III)klorida 10\%. Jika terjadi warna biru tua atau hitam kehijauan menunjukkan adanya tanin [5].

\section{e. Uji Steroid dan Triterpenoid}

Sebanyak $2 \mathrm{~mL}$ ekstrak ditambahkan $\mathrm{CH}_{3} \mathrm{COOH}$ glasial sebanyak 10 tetes dan $\mathrm{H}_{2} \mathrm{SO}_{4}$ pekat sebanyak 2 tetes. Larutan dikocok perlahan dan dibiarkan selama beberapa menit. Adanya steroid ditunjukan oleh warna biru atau hijau, sedangkan triterpenoid memberikan warna merah atau ungu [3].

\section{f. Uji Saponin}

Sebanyak 2-3 mL ekstrak dimasukkan ke dalam tabung reaksi, kemudian ditambahkan $10 \mathrm{~mL}$ air panas lalu didinginkan, kemudian dikocok kuat-kuat selama 10 detik lalu ditambahkan 1 tetes $\mathrm{HCl} 2 \mathrm{~N}$. Uji positif ditunjukkan dengan terbentuknya buih yang stabil setinggi 1-10 cm selama tidak kurang dari 10 menit [1].

\section{Uji Antioksidan}

Diambil $2 \mathrm{~mL}$ larutan ekstrak kemudian ditambahkan dengan $2 \mathrm{~mL}$ larutan DPPH 40 ppm. Dibuat variasi konsentrasi sampel seperti terlihat pada Tabel 1. Campuran larutan ini dihomogenkan dengan menggunakan vorteks dan dibiarkan di tempat gelap pada suhu kamar selama 30 menit. Kemudian diukur absorbansinya pada panjang gelombang maksimumnya. Dilakukan juga pengukuran absorbansi blanko. Hasil penetapan antioksidan dibandingkan dengan vitamin $\mathrm{C}$ Besarnya daya antioksidan dihitung dengan rumus : 
$\%$ Aktivitas $=\frac{\text { Abs blanko }- \text { abs sampel }}{\text { absorbansi blanko }} \times 100 \%$

Tabel 1. Variasi konsentrasi sampel aktivitas antioksidannya

\begin{tabular}{ccc}
\hline No & $\begin{array}{c}\text { Ekstrak/ } \\
\text { Fraksi }\end{array}$ & $\begin{array}{c}\text { Konsentrasi } \\
(\mathrm{ppm})\end{array}$ \\
\hline & & 20 \\
& & 40 \\
1 & Metanol & 60 \\
& & 80 \\
& & 100 \\
\hline & & 10 \\
2 & Etil Asetat & 20 \\
& & 30 \\
& & 40 \\
& & 50 \\
\hline \multirow{3}{*}{3} & & 20 \\
& & 40 \\
& & 60 \\
& & 80 \\
\end{tabular}

\section{HASIL DAN PEMBAHASAN}

Skrining fitokimia merupakan metode pendekatan yang dapat digunakan dalam menentukan keberadaan senyawa metabolit sekunder tanaman. Golongan senyawa metabolit sekunder ditentukan secara kualitatif dengan melihat adanya perubahan warna, pengendapan atau pembentukan busa sesuai dengan pereaksi yang digunakan sampel kulit batang Pilapila.

Kulit Batang Pila-pila mempunyai potensi sebagai antioksidan alami. Kulit Batang Pila-pila mengandung golongan senyawa fenolik, flavanoid, alkaloid, tannin, dan steroid merupakan komponen senyawa antoksidan, seperti terlihat pada Tabel 2. Kemudian dilakukan uji aktivitas antioksidan pada ekstrak metanol dan fraksi dari kulit batang Pilapila (Mallotus paniculatus).

Tabel 2. Uji Golongan Metabolit Sekunder Sampel Kulit Batang Pila-pila

\begin{tabular}{cccc}
\hline Gol Met. Sekunder & Ekstrak & N-heksan & Etil Asetat \\
\hline Alkaloid & + & + & + \\
Tanin & + & + & + \\
Saponin & - & - & - \\
Fenolik & + & + & + \\
Flavanoid & + & + & + \\
Steroid/Triterpenoid & + & + & + \\
\hline
\end{tabular}

Ekstrak metanol, n-heksan, dan etil asetat diuji aktivitas antioksidannya dengan metode penangkapan radikal bebas DPPH dengan menggunakan beberapa konsentrasi, yaitu 
masing-masing; 20,40,60,80, dan 100 ppm untuk ekstrak kasar dan fraksi n-heksan dan untuk fraksi etil menggunakan konsentrasi 10,20,30,40, dan 50 ppm.

Penentuan aktivitas antioksidan dilakukan dengan menghitung nilai konsentrasi penghambatan (IC50). Nilai IC50 diperoleh dari persamaan $\mathrm{y}=\mathrm{ax}+\mathrm{b}$ pada kurva regresi linear hubungan konsentrasi (x) dan persentase peredaman (y). Nilai IC50 merupakan konsentrasi efektif yang dibutuhkan untuk menghambat sebesar $50 \%$ dari konsentrasi radikal DPPH. Hasil dari penentuan nilai IC50 didapat dari persamaan kurva regresi linear dari persentase penghambatan sebagai sumbu y dan konsentrasi antioksidan pada sumbu x yang ditampilkan pada Gambar 1,2 dan 3 dari ketiga sampel.

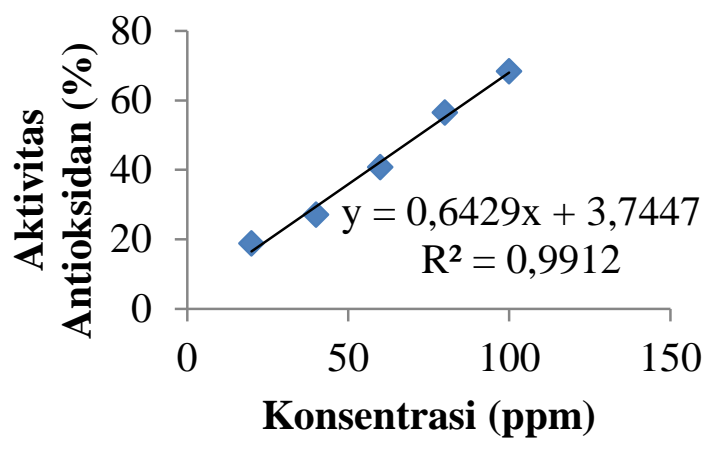

Gambar 1. Kurva regresi linear ekstrak metanol dari kulit batang Pila-pila.

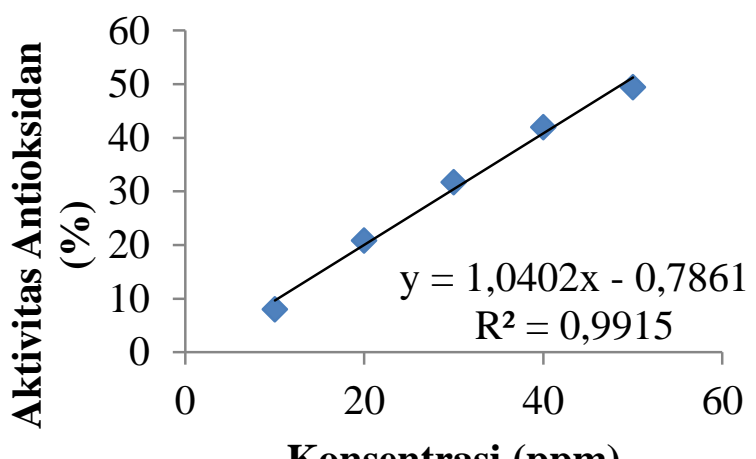

Konsentrasi (ppm)

Gambar 2. Kurva regresi linear fraksi n-heksan

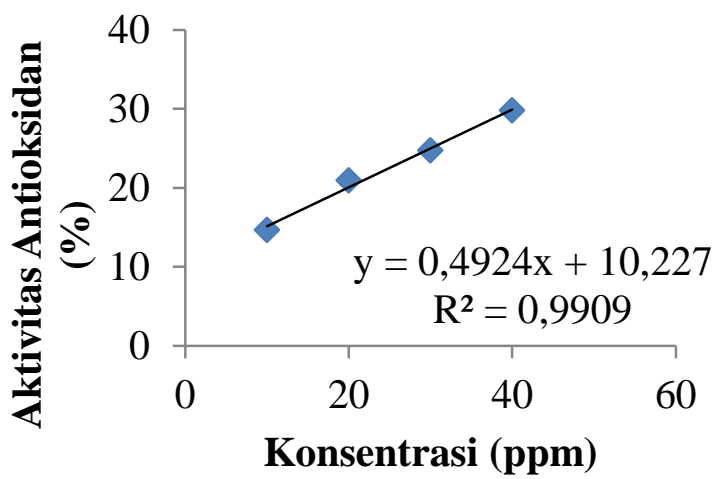


Nilai IC50 dihitung dengan cara memasukkan nilai 50\% ke dalam persamaan regresi linear sebagai sumbu y kemudian dihitung nilai x sebagai konsentrasi IC50. Persamaan regresi linear memiliki nilai b yang positif, sehingga menunjukkan bahwa kurva nilai penghambatan antioksidan merupakan kurva peningkatan. Koefisien b merupakan koefisien arah regresi linier dan menyatakan perubahan rata-rata variabel y untuk setiap perubahan variabel x sebesar satu unit. Dari data terlihat pada ekstrak metanol, didapatkan nilai $b=+$ 46,161, sehingga dapat dikatakan untuk setiap x (konsentrasi sampel) bertambah $1 \mathrm{ppm}$, maka y (\%inhibisi) bertambah / meningkat sebesar 46,161. (Mardawati, dkk., 2008).

Berdasarkan persamaan yang didapat, selanjutnya ditentukan nilai IC50. Nilai IC50 pada ekstrak metanol kulit batang Ceria yang dihasilkan adalah sebesar $56,47 \mu \mathrm{g} / \mathrm{mL}$. Menurut Zuhra dkk., 2008, nilai IC50 dianggap sebagai ukuran yang baik untuk efisiensi antioksidan senyawa-senyawa murni ataupun ekstrak. Semakin kecil nilai IC50 berarti semakin tinggi aktivitas antioksidannya.

Secara spesifik suatu senyawa dikatakan sebagai antioksidan sangat kuat jika nilai IC50 kurang dari 50ppm, kategori kuat untuk IC50 bernilai 50-100ppm, kategori sedang jika bernilai 101-150ppm dan untuk kategori lemah jika nilai IC50 bernilai 151-200ppm. Sampel yang memiliki nilai IC50>200ppm dianggap tidak bersifat antioksidan.

Besarnya aktivitas penangkapan radikal bebas DPPH ditandai dengan nilai IC50 (50\% Inhibitory concentration). DPPH menghasilkan radikal bebas aktif bila dilarutkan dalam metanol. Radikal bebas tersebut stabil dengan absorpsi maksimum pada panjang gelombang 515-520 nm dan dapat direduksi oleh senyawa antioksidan. Metode penangkapan radikal bebas DPPH dipilih karena sederhana, mudah, cepat, peka dan hanya memerlukan sedikit sampel. Pada pelaksanaan uji antioksidan sampel kulit batang Pila-pila (Mallotus paniculatus.) diawali dengan pembuatan spektra sinar tampak (360-720 nm) untuk mengamati apakah larutan DPPH mempunyai panjang gelombang dan absorbansi yang masuk dalam rentang.

Uji aktvitas antioksidan penangkapan radikal bebas DPPH menunjukkan bahwa ekstrak metanol, n-heksan,, etil asetat dan mempunyai IC50 berturut-turut adalah 71.94 ppm, $58.92 \mathrm{ppm}$ dan $49.92 \mathrm{ppm}$.

Hasil uji aktivitas antioksidan menunjukkan bahwa ketiga ekstrak dan fraksi kulit batang Pila-pila (Mallotus paniculatus) memiliki aktivitas sebagai antioksidan, kategori kuat untuk ekstrak metanol dan fraksi n-heksan, sedangkan untuk fraksi etil asetat sangat kuat.

Aktivitas antioksidan dari ekstrak kulit batang Pila-pila (Mallotus paniculatus) berkaitan dengan kandungan senyawa yang terdapat pada masing-masing ekstrak. Metanol merupakan pelarut yang bersifat polar yang dapat mengekstraksi senyawa polar dan non polar, sehingga kemungkinan semua senyawa yang terkandung di dalam kulit batang Pilapila (Mallotus paniculatus) seperti tannin, katekin, fenol dan steroid dapat terekstraksi. Ekstrak n-heksan diduga mengandung senyawa steroid, lemak atau minyak, senyawasenyawa ini bersifat non polar sehingga dapat terekstraksi ke pelarut nheksan, beberapa senyawa steroid dan lemak atau minyak memiliki aktivitas antioksidan.

Hasil uji aktivitas antioksidan menunjukkan bahwa ekstrak etil asetat memiliki nilai IC50 49, ppm. Hal ini menunjukkan bahwa ekstrak etil asetat kulit batang Pila-pila (Mallotus paniculatus.) pada konsentrasi 49, ppm telah mampu menghambat radikal bebas DPPH sebanyak 50\%. Berdasarkan hasil tersebut dapat dikatakan bahwa ekstrak etil asetat mempunyai aktivitas antioksidan yang sangat kuat dalam menghambat radikal bebas DPPH, karena pada konsentrasi kurang dari 50 ppm telah dapat menghambat 50\% radikal bebas DPPH. aktivitas antioksidan ekstrak metanol dan fraksi n-heksan kulit batang Pila-pila (Mallotus paniculatus) masih lebih rendah. Hal ini dikarenakan pada penelitian ini yang diuji masih berupa ekstrak kasar, sedangkan pada fraksi n-heksan masih terdapat banyak senyawa 
pengotor sehingga masih ada kemungkinan senyawa murni yang dikandung memiliki aktivitas antioksidan yang lebih kuat dibandingkan ekstraknya.

Kemampuan menghambat radikal bebas DPPH tersebut berkaitan pula dengan senyawa fitokimia dan gugus hidroksi yang terdapat pada senyawa tersebut. Pila-pila (Mallotus paniculatus.) mengandung senyawa fenolik. Senyawa fenolik yang banyak terdapat pada kulit batang adalah tannin yang merupakan bentuk senyawa polifenol yang banyak terdapat gugus hidroksil. Sehingga ekstrak etil asetat memiliki aktivitas antioksidan yang lebih kuat dibandingkan dengan ekstrak yang lainnya.

\section{KESIMPULAN DAN SARAN}

\section{Kesimpulan}

Dari penelitian yang telah dilakukan dapat disimpulkan bahwa ekstrak kulit Pila-pila (Mallotus paniculatus) memiliki aktivitas antioksidan. Hasil uji aktivitas antioksidan menunjukkan bahwa nilai IC50 dari ekstrak metanol, n-heksan dan etil asetat berturut-turut adalah 71.94 ppm, $58.92 \mathrm{ppm}$ dan $49.92 \mathrm{ppm}$.

\section{Saran}

Sebaiknya dilakukan penelitian untuk mengisolasi senyawa aktif antioksidan dari kulit Pila-pila (Mallotus paniculatus) dan uji bioaktivitas.

\section{DAFTAR PUSTAKA}

Depkes RI., 1995. Farmakope Indonesia. Departemen Kesehatan Republik Indonesia:Jakarta.

Farsnworth, N. R. 1966. Biological and Phytochemical Screening of Plant. Journal of Pharmaceutical Sciences. 55: 59.

Harborne, J.B., 1996. Metode Fitokimia.Terjemahan: Padmawinata, K dan Soediro, I. InstitutTeknologi Bandung:Bandung.

JFW, Slik. 2009. Asianplant.Net: Plants of Southeast Asia. Diunduh tanggal 15 April 2016.

Jones, W.P., Kinghorn, A.D., 2006. Extraction of Plant Secondary Metabolites. In: Sharker, S.D. Latif Z., Gray A.L, eds. Natural Product Isolation. 2nd edition. Humana Press: New Jersey.

Mardawati, E, Filianty, F dan Marta, H, 2008, Kajian Aktivitas Antioksidan Ekstrak Kulit Manggis (Garcinia mangostana) dalam Rangka Pemanfaatan Limbah Kulit Manggis di Kecamatan Puspahiang Kabupaten Tasikmalaya., Laporan Akhir Penelitian

Sulistyarini PD. 2009. Uji Aktivitas Antiradikal Bebas dari Ekstrak Inti Biji Bagore (Caesalpinia crista Linn.). Skripsi Fakultas Farmasi Universitas Hasanuddin. Makassar. hal. 37-38.

Wahjuni T. 2006. Dua Santon Terprenilasi dan Uji Antioksidan pada Ekstrak n-Heksan dari Kulit Batang Garcinia tetranda Pierre. Tesis Program Pascasarjana ITS. Surabaya. hal. 35 . 